\title{
Correction to: Effect of chemoradiotherapy on the proportion of circulating lymphocyte subsets in patients with limited-stage small cell lung cancer
}

\author{
Yamei Chen ${ }^{1} \cdot$ Ying Jin ${ }^{1,2} \cdot$ Xiao $\mathrm{Hu}^{1,3} \cdot$ Ming Chen ${ }^{1,3}$
}

Published online: 16 April 2021

○) Springer-Verlag GmbH Germany, part of Springer Nature 2021

\section{Correction to: Cancer Immunology, Immunotherapy https://doi.org/10.1007/s00262-021-02902-x}

The original version of this article unfortunately contained a mistake. The presentation of Figure 1 and Table 1 was incorrect. The corrected Fig. 1 and Table 1 is given in the following page.

The original article has been corrected.

Publisher's Note Springer Nature remains neutral with regard to jurisdictional claims in published maps and institutional affiliations.

The original article can be found online at https://doi.org/10.1007/ s00262-021-02902-x.

Ming Chen

chenming@zjcc.org.cn

1 Zhejiang Key Laboratory of Radiation Oncology, The Cancer Hospital of the University of Chinese Academy of Sciences (Zhejiang Cancer Hospital), Institute of Basic Medicine and Cancer (IBMC), Chinese Academy of Sciences, Hangzhou 310022, Zhejiang, China

2 Department of Medical Oncology, The Cancer Hospital of the University of Chinese Academy of Sciences (Zhejiang Cancer Hospital), Institute of Basic Medicine and Cancer (IBMC), Chinese Academy of Sciences, Hangzhou 310022, Zhejiang, China

3 Department of Radiation Oncology, The Cancer Hospital of the University of Chinese Academy of Sciences (Zhejiang Cancer Hospital), Institute of Basic Medicine and Cancer (IBMC), Chinese Academy of Sciences, Hangzhou 310002, Zhejiang, China 

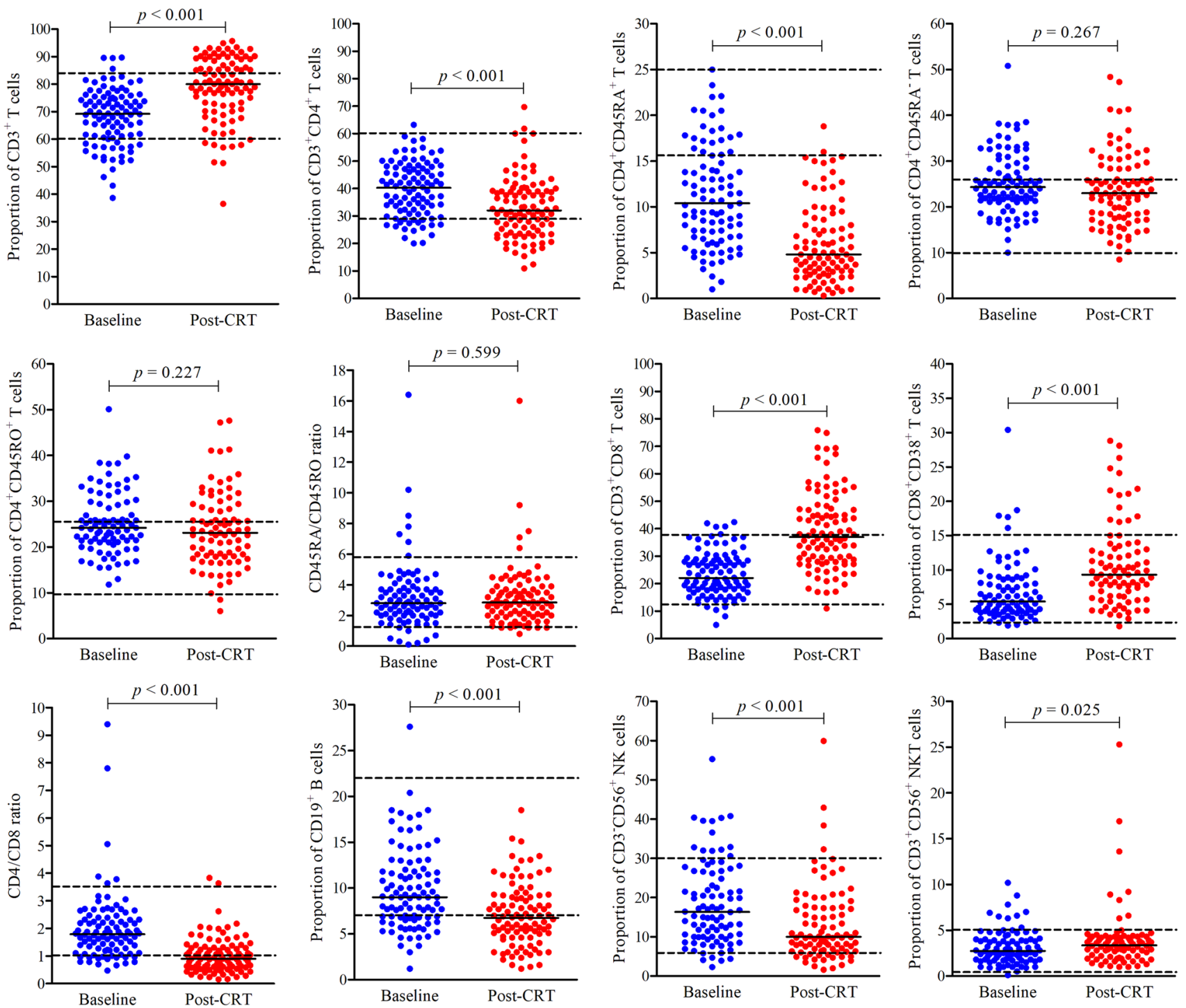

Fig. 1 Percentages of lymphocyte subsets in peripheral blood before and after chemoradiotherapy in LS-SCLC patients. A two related sample nonparametric test was used for statistical analysis and the charts represented the median \% (min to max) deviation for the pro

portion of each lymphocyte during treatment. The baseline values represented those prior to any treatment. Post-CRT represented the values at three months after chemoradiotherapy. The dotted line represents the normal reference range 
Table 1 Clinical features of 98 patients with LS-SCLC

\begin{tabular}{|c|c|c|c|}
\hline Characteristic & $N(\%)$ or median range & Characteristic & $N(\%)$ or median range \\
\hline Gender & & 3.0 & $11(11.2)$ \\
\hline Male & 79 (80.6) & RT frequency & \\
\hline Female & $19(19.4)$ & Qd & $49(50.0)$ \\
\hline Age (years) median (range) & $62(38-75)$ & Bid & $49(50.0)$ \\
\hline Smoking history & & RT fraction & \\
\hline Non-smoker & $21(21.4)$ & Median (range) & $30(15-36)$ \\
\hline Smoker & 77 (78.6) & Total dose of RT (Gy) & \\
\hline Primary tumor site & & Median (range) & $45(43.5-60)$ \\
\hline Left & $51(51.0)$ & CRT method & \\
\hline Right & $47(48.0)$ & Concurrent & $64(65.3)$ \\
\hline Chemo-regimen & & Sequential & $34(34.7)$ \\
\hline EP & $86(87.8)$ & CRT efficiency & \\
\hline $\mathrm{EC}$ & $12(12.2)$ & CR & $31(31.6)$ \\
\hline Chemo-cycle & & PR & $60(61.2)$ \\
\hline Median (range) & $4.5(2-6)$ & SD & $7(7.2)$ \\
\hline RT dose/fraction (Gy) & & PCI treatment & \\
\hline 1.5 & $49(50.0)$ & No & $23(23.5)$ \\
\hline 2.0 & $38(38.8)$ & Yes & $75(76.5)$ \\
\hline
\end{tabular}

